\title{
Optimizing Patient Risk Stratification for Colonoscopy Screening and Surveillance of Colorectal Cancer: The Role for Linked Data
}

\author{
David B. Preen ${ }^{1 *}$, Iris Lansdorp-Vogelaar ${ }^{2}$, Hooi C. Ee ${ }^{3}$, Cameron Platell, \\ Dayna R. Cenin ${ }^{1,2}$, Lakkhina Troeung ${ }^{1}$, Max Bulsara ${ }^{1,5}$ and Peter O'Leary ${ }^{6}$ \\ ${ }^{1}$ Centre for Health Services Research, School of Population and Global Health, The University of Western Australia, \\ Perth, WA, Australia, ${ }^{2}$ Department of Public Health, Erasmus University Medical Centre, Rotterdam, Netherlands, \\ ${ }^{3}$ Department of Gastroenterology, Sir Charles Gairdner Hospital, Nedlands, WA, Australia, ${ }^{4}$ Colorectal Cancer Research \\ Unit, The University of Western Australia, Perth, WA, Australia, ${ }^{5}$ Institute for Health Research, University of Notre Dame, \\ Fremantle, WA, Australia, ${ }^{6}$ Faculty of Health Sciences, Curtin University, Perth, WA, Australia
}

Keywords: colorectal cancer, colonoscopy, screening, clinical guidelines, adenoma, risk stratification

OPEN ACCESS

Edited by: Matthew Bellgard, Murdoch University, Australia

Reviewed by:

Jim Codde,

University of Notre Dame Australia, Australia

Michael Black,

Pathwest Laboratory Medicine,

Australia

*Correspondence:

David B. Preen

david.preen@uwa.edu.au

Specialty section:

This article was submitted to Public Health Policy, a section of the journal

Frontiers in Public Health

Received: 31 January 2017

Accepted: 18 August 2017

Published: 08 September 2017

Citation:

Preen DB, Lansdorp-Vogelaar I,

Ee HC, Platell C, Cenin DR,

Troeung L, Bulsara M and O'Leary $P$

(2017) Optimizing Patient Risk

Stratification for Colonoscopy

Screening

and Surveillance of Colorectal

Cancer: The Role for Linked Data.

Front. Public Health 5:234.

doi: 10.3389/fpubh.2017.00234

\section{INTRODUCTION}

Colorectal cancer (CRC) is the third most common cancer worldwide, with an estimated 1.4 million new cases and almost 700,000 related deaths globally each year (1). In Australia, CRC is the second most commonly reported cancer and second most common cause of cancer-related death (2). Moreover, Australia has the fourth highest incidence of CRC for men and fifth highest for women internationally $(3,4)$. Incidence rates of CRC have at least doubled in many countries since the mid1970s (5-7), although trends vary across countries with stabilizing or declining rates in more recent years reported in Western Europe and the United States (US), respectively. This trend is reversed for high-income nations that have recently made the transition from low-income economies $(8,9)$.

In the majority of cases, CRC develops from non-malignant precursor adenomatous colonic polyps (adenomas) (10), with the overall adenoma burden dependent on the number, size, villosity, dysplasia grade, and location of adenomas in the colon. Importantly, the average interval from adenoma appearance to development of CRC is $>10$ years (11), and the removal of adenomas reduces CRC incidence and mortality $(12,13)$. This affords an excellent opportunity for early detection through screening and regular colonoscopic surveillance, and the condition meets the World Health Organization criteria for diseases suited to screening (14). Patients with prior adenoma are therefore recommended to undergo regular surveillance colonoscopy (15). Increased surveillance, in addition to advances in surgical and adjuvant therapy (16), has been shown to reduce CRC incidence and increase median 5 -year survival for CRC from $55.0 \%$ in the early 1980 s to $65.3 \%$ by 2005 (16).

Lifetime prevalence of adenoma is $40-50 \%$ (17), however, the majority of adenomas never develop into malignant neoplasms and only $4-5 \%$ of the population eventually develop CRC (18). Consequently, simply identifying the presence of adenomas does not represent the most efficient approach for making informed recommendations for the need and timing of follow-up colonoscopic surveillance and the overall adenoma burden and specific adenoma characteristics should be factored into clinical decision making $(12,13)$.

\section{USE OF COLONOSCOPY FOR CRC DETECTION}

Although some population-based screening programs exist employing fecal occult blood testing (FOBT), colonoscopy remains the "gold-standard" for detection of CRC and precursor adenomas 
(19). However, others have suggested that colonoscopy is overused as a primary screening and surveillance tool leading to sizable increases in the rates of colonoscopy in many countries (20-22).

In Australia, rising usage of colonoscopy has been seen for over two decades, with Medicare claims for the procedure increasing by $250 \%$ in the last 10 years (23). This increase has occurred simultaneously with increased capacity within the private hospital sector (24). Given the current trajectory, and when considered with population aging and the promotion of earlier screening, it is estimated that over 1 million colonoscopies will be performed annually by 2020 in Australia (population 24 million) (25). Similar relative trends have been reported elsewhere, with greater absolute increases, in countries such as the US (26). Such demand is not sustainable for most health systems, both in terms of provider capacity and health-care costs, estimated to be in the multiple billions of dollars annually in western nations (27). Furthermore, if projected increases in demand are realized, access to this service will be compromised, especially in public health systems. Already in Australia waiting times for colonoscopy exceeding 250 days are not uncommon $(28,29)$.

\section{RISK STRATIFICATION APPROACHES TO CRC DETECTION AND PREVENTION}

Researchers, including our team, have previously called for greater consideration of personalized risk stratification approaches to primary screening for CRC (30); however, less consideration has been given to the potential benefits of such approaches for ongoing surveillance. Targeting colonoscopy to patients who stand to benefit most (i.e., those at higher risk of CRC) through robust risk stratification would reduce the burden of colonoscopies to both patients and the health system, while maintaining the preventive benefits of surveillance colonoscopy. Such targeting could reduce burden for lower-risk patients, who are less likely to benefit and reduce waiting times for high-risk patients who require more regular surveillance. In addition, as most adenoma patients face a lifetime of burdensome colonoscopies with its associated bowel preparation and procedural risks, targeting surveillance to high-risk patients would also likely increase compliance with recommended follow-up colonoscopy intervals, which is often poor; only $36 \%$ of patients comply with clinical guideline recommended intervals for surveillance colonoscopy in Australia (31). Moreover, with increasing incidence in CRC seen in younger age groups $(32,33)$, especially those under eligibility age thresholds for FOBT programs (34), and differential surveillance colonoscopy compliance based on patient insurance status (35), risk stratification holds additional benefits for particular patient groups.

The literature on risk stratification for CRC prevention primarily incorporates factors such as family history and sociodemographics (age, sex, and socioeconomic status) with some models also incorporating genetic variants associated with CRC susceptibility (36). Where surveillance colonoscopy is considered, adenoma number, size, villosity, and dysplasia grade at the most recent investigation are the more common determinants for recommending future surveillance intervals, whereas other factors including proximal or distal adenoma location, and the total adenoma burden over time are often overlooked as risk factors for future CRC.

\section{INCORPORATING DATA FROM MULTIPLE PRIOR COLONOSCOPIES}

The cumulative burden of prior colorectal adenoma has almost exclusively been omitted from risk stratification approaches for surveillance colonoscopy, often due to unavailability of data. Most research in this area has only incorporated data from the most recent colonoscopy. However, it is likely that the risk of adenoma recurrence or development of CRC is modified by prior adenoma and/or changes in adenoma characteristics over time. Therefore, risk increases are likely conditional on adenoma characteristics from multiple earlier examinations rather than just the most recent investigation.

To date, there has been little published work which has considered longitudinal colonoscopy history for risk prediction of CRC. Estimates from a relatively small study $(n<3,000)$ of Dutch patients investigated predictive ability of baseline colonoscopy on adenoma burden for up to two subsequent colonoscopies (37). The authors reported that optimizing timing of colonoscopy surveillance by incorporating multiple risk factors could result in $20 \%$ fewer surveillance colonoscopies being required annually, while maintaining the same level of effectiveness in terms of cancer detection and life-years gained (37). Three other studies have reported on rates of advanced adenoma or CRC incorporating up to two surveillance colonoscopies (38-40), although, as commented by the US Multi-Society Task Force on Colorectal Cancer (41), all have important limitations possibly resulting in selection bias. Despite these weaknesses, findings were consistent across these studies suggesting that accounting for longitudinal colonoscopy history could provide important information for CRC risk prediction. While these results are encouraging, there is currently a complete lack of findings in the literature beyond the second surveillance colonoscopy. Consequently, the extent to which adenoma burden over a patient's life mediates future CRC risk is largely unknown.

Due to the lack of empirical data in this area, recommended intervals for follow-up colonoscopy in most national clinical guidelines, such as those in the US, UK, Australia, and Europe $(15,41-43)$, are almost exclusively based on results of the latest examination alone. Consequently, existing international guidelines are arguably a compromise that may not accurately define optimal intervals for repeat surveillance in patients with detected adenomas over multiple prior colonoscopies.

In Australia, clinical guidelines advocate that a risk assessment combining the results at baseline and at least one repeat surveillance examination may be a superior tool for CRC prediction than reliance on findings at the latest examination (15). However, there is no guidance provided on how to use that information other than a general statement that endoscopists should be encouraged to consider previous colonoscopy findings. The authors of the Australian Clinical Guidelines for Colonoscopy Surveillance recognize this limitation and recommend further research to 
determine CRC risk after a series of surveillance examinations, stratified by risk parameters of the baseline adenomas (15). This has also been highlighted as an important area in an Australian gap analysis (44).

\section{OPPORTUNITIES IN THE CURRENT DATA ENVIRONMENT}

The emergence of whole-population data linkage systems in many countries has afforded the opportunity to combine comprehensive data from a range of health service data collections for large samples over decades. Such linkage systems provide a powerful resource for conducting longitudinal research on large or even entire populations and have benefits for minimizing, if not overcoming, limitations due to sample size, selection bias, response or recall bias, loss-to-follow-up, and ascertainment of accurate health service exposure and outcome measures. The use of such data has become commonplace in health research (45), and linkage of whole-population non-consented service data for research purposes is an accepted ethical approach (46).

Data from such linkage systems could also lay the foundation for more robust risk stratification of populations, incorporating a wide range of sociodemographic, clinical, and genetic factors depending on the data available to be linked. Linkage systems, such as the Western Australian Data Linkage System (47), use widely accepted probabilistic-matching techniques and already have capacity to link decades of cancer registry, inpatient, pathology, and mortality data, combined with the ability to genealogically link patients at the individual-level to derive familial history of disease and "genetic" risk factors. Such data provide a unique platform to investigate different risk stratification models for CRC detection through colonoscopy surveillance. Moreover, due to the extensive observation periods that can be investigated, these systems provide the opportunity to incorporate data based on findings over multiple surveillance colonoscopies, which have been omitted from the literature to date but are likely an important component for precision targeting of ongoing surveillance windows. Additional linkage to National Bowel Cancer Screening Program records and large cohort studies, which may provide information on a range of health behaviors not routinely captured in administrative data such as smoking, alcohol consumption, diet, and physical activity would further enhance the ability to precisely stratify CRC risk and tailor appropriate follow-up intervals. The lack of such behavioral risk factor information, rarely captured in administrative data, is a potential limitation and arguably does not allow all risk factors to be considered in risk stratification models. However, available administrative data do allow targeting of factors most relevant to guideline-based decision making in this area. Furthermore, the approach proposed in this paper would still provide an advance on existing risk-stratification models as a result of accounting for the cumulative burden of prior colorectal adenoma which has been omitted from risk stratification approaches to CRC screening and surveillance to date.

In addition, when combined with the availability of tools such as MISCAN-Colon, a well-established microsimulation model for CRC $(48,49)$, evaluation of the cost-effectiveness of different risk stratification models for informing timing of ongoing follow-up colonoscopy for CRC is possible. Such work can also be tailored to jurisdictional-specific settings and precedents exist for the adaption of the MISCAN-Colon model to local settings, such as the Australian-specific variant of MISCAN-Colon (50).

\section{CONCLUSION}

Whole-population data linkage systems are uniquely placed to allow robust longitudinal investigation to develop risk stratification models for CRC surveillance. Systems would require the capacity to link data collections comprising demographic, cancer registry, hospital inpatient, pathology, mortality, and genealogical factors over multiple decades at the whole-of-population level. The ability to link additional behavioral risk factor data (e.g., smoking, alcohol consumption, and dietary intake) from sources such as large cohort studies would also add value. The linking of such data collections would allow relevant risk factors to be accounted for in risk stratification models, including the incorporation of complete colonoscopy history and adenoma burden over time, which represents a potentially important modifying factor for cancer risk but is currently not included in risk modeling for recurrent adenoma of CRC.

In addition to providing greater precision with patient risk profiling, estimates can be used in cost-effectiveness analyses to determine optimal colonoscopy surveillance intervals for patients at different levels of cancer risk. This could reduce costs to the health system without a reduction in the number of CRCs that surveillance colonoscopy prevents. Such information also has capacity to support rational decisions concerning the best strategy for repeat surveillance via colonoscopy for patients at both low and high risk for CRC and reduce excessive delays for surveillance colonoscopy, especially for high-risk patients. Moreover, it creates an evidence-base for recommendations that would be immediately implementable in clinical practice with the potential to influence national colonoscopy surveillance guidelines.

\section{AUTHOR CONTRIBUTIONS}

DP was the lead investigator for the project to which this opinion piece relates and was responsible for concept development, undertaking the relevant literature critique and drafting the initial manuscript. IL-V provided direct health economics and colorectal cancer screening expert input and was involved (along with DP) with developing the overall concept. PO and DC provided genetic and risk stratification for cancer screening input. $\mathrm{HE}$ and $\mathrm{CP}$ provided colorectal clinical and surgical input. $\mathrm{MB}$ and LT provided methodological expertise. All the authors were involved with developing the manuscript and provided detailed feedback and commentary on all iterations of the draft paper.

\section{FUNDING}

This paper arises from a project grant funded by the Australian National Health and Medical Research Council (NHMRC) (APP1123495). 


\section{REFERENCES}

1. International Agency for Research on Cancer. Colorecatal Cancer: Estimated Incidence, Mortality and Prevalence Worldwide in 2012. World Health Organisation (2016). Available from: http://globocan.iarc.fr/Pages/ fact_sheets_cancer.aspx

2. Australasian Association of Cancer Registries. Cancer in Australia: An Overview. Cancer Series 2012; no. 74. Cat. no. CAN 70.

3. Ferlay J, Soerjomataram I, Dikshit R, Eser S, Mathers C, Rebelo M, et al. Cancer estimated incidence, mortality and prevalence worldwide: sources, method and major patterns in GLOBOCAN 2012. Int J Cancer (2015) 136(5):E359-86. doi:10.1002/ijc. 29210

4. National Cancer Insitute. Age-Adjusted Colorectal Cancer Incidence and Mortality Rates for 2008 for 32 Countries 2015. (2017). Available from: http://healthcaredelivery.cancer.gov/icsn/colorectal/mortality.html

5. American Cancer Society. Cancer Facts \& Figures for African Americans 2005-2016. (2016). Available from: http://www.cancer.org/docroot/STT/ stt_0.asp

6. Boyle P, Ferlay J. Mortality and survival in breast and colorectal cancer. Nat Clin Pract Oncol (2008) 2(9):424-5. doi:10.1038/ncponc0288

7. National Institutes of Health. What You Need To Know About Cancer of the Colon and Rectum. Maryland: US Department of Health and Human Services \& National Institutes of Health (2006).

8. Boyle P, Langman JS. ABC of colorectal cancer: epidemiology. BMJ (2000) 321(7264):805-8. doi:10.1136/bmj.321.7264.805

9. World Cancer Research Fund and American Institute for Cancer Research. Food, Nutrition, Physical Activity, and the Prevention of Cancer: A Global Perspective. Washington, DC: American Institute for Cancer Research (2007).

10. Morson BC. The evolution of colorectal carcinoma. Clin Radiol (1984) 35(6):425-31. doi:10.1016/S0009-9260(84)80033-1

11. Winawer SJ, Fletcher RH, Miller L, Godlee F, Stolar MH, Mulrow CD, et al. Colorectal cancer screening: clinical guidelines and rationale. Gastroenterology (1997) 112(2):594-642. doi:10.1053/gast.1997.v112.agast970594

12. Martínez M, Baron JA, Lieberman DA, Schatzkin A, Lanza E, Winawer SJ, et al. A pooled analysis of advanced colorectal neoplasia diagnoses after colonoscopic polypectomy. Gastroenterology (2009) 136(3):832-41. doi:10.1053/j. gastro.2008.12.007

13. van Heijningen E, Lansdorp-Vogelaar I, Kuipers EJ, Dekker E, Lesterhuis W, Ter Borg F, et al. Features of adenoma and colonoscopy associated with recurrent colorectal neoplasia based on a large community-based study. Gastroenterology (2013) 144(7):1410-8. doi:10.1053/j.gastro.2013. 03.002

14. Wilson J, Junger G. Principles and practice of screening for disease. Public Health Paper No 34. Geneva: World Health Organization (1968).

15. Cancer Council Australia Colonoscopy Surveillance Working Party. Clinical Practice Guidelines for Surveillance Colonoscopy in Adenoma Follow-Up; Following Curative Resection of Colorectal Cancer; and for Cancer Surveillance in Inflammatory Bowel Disease. Sydney: Cancer Council Australia (2011).

16. Howlader N, Noone AM, Krapcho M, Garshell J, Miller D, Altekruse SF, et al. SEER Cancer Statistics Review, 1975-2013. Bethesda, MD: National Cancer Institute (2016). Available from: http://seer.cancer.gov/csr/1975_2012/

17. Rex D, CB W, Hofstad B, editors. Colon Polyps: Prevalence, Incidence and Growth Rates. Oxford: Blackwell (2003).

18. ACIM (Australian Cancer Incidence and Mortality) Books: Colorectal (Bowel) Cancer. Australian Institute of Health and Welfare (2017). Available from: http://www.aihw.gov.au/acim-books/

19. Smith GA, O'Dwyer PJ. Sensitivity of double contrast barium enema and colonoscopy for the detection of colorectal neoplasms. Surg Endosc (2001) 15:649-52. doi:10.1007/s004640000372

20. Bian J, Bennett C, Cooper G, D’Alfonso A, Fisher D, Lipscomb J, et al. Assessing colorectal cancer screening adherence of Medicare fee-for-service beneficiaries age 76 to 95 years. J Oncol Pract (2016) 12(6):e670-80. doi:10.1200/ JOP.2015.009118

21. Johnson MR, Grubber J, Grambow SC, Maciejewski ML, Dunn-Thomas T, Provenzale D, et al. Physician non-adherence to colonoscopy interval guidelines in the veterans affairs healthcare system. Gastroenterology (2015) 149(4):938-51. doi:10.1053/j.gastro.2015.06.026
22. Kruse GR, Khan SM, Zaslavsky AM, Ayanian JZ, Sequist TD. Overuse of colonoscopy for colorectal cancer screening and surveillance. J Gen Intern Med (2015) 30(3):277-83. doi:10.1007/s11606-014-3015-6

23. National Bowel Cancer Screening Program Working Group. Improving Colonoscopy Services in Australia. Canberra: Australian Government Department of Health and Ageing (2009).

24. Review of MBS Colonoscopy Items. Department of Health and Ageing (2011). Available from: http://www.health.gov.au/internet/main/publishing. nsf/Content/Colonoscopy_Review

25. Pignone MP, Flitcroft KL, Howard K, Trevena LJ, Salkeld GP, St John DJB. Costs and cost-effectiveness of full implementation of a biennial faecal occult blood test screening program for bowel cancer in Australia. Med J Aust (2011) 194(4):180-5.

26. Klabunde CN, Cronin KA, Breen N, Waldron WR, Ambs AH, Nadel MR. Trends in colorectal cancer test use among vulnerable populations in the United States. Cancer Epidemiol Biomarkers Prev. (2011) 20(8):1611-21. doi:10.1158/1055-9965.EPI-11-0220

27. Ladabaum U, Song K. Projected national impact of colorectal cancer screening on clinical and economic outcomes and health services demand. Gastroenterology (2005) 129(4):1151-62. doi:10.1053/j.gastro.2005.07.059

28. Viiala CH, Tang KW, Lawrence IC, Murray K, Olynyk JK. Waiting times for colonoscopy and colorectal cancer diagnosis. Med JAust (2007) 186(6):282-5.

29. Miles J. QLD health complaints commissioner demands open waiting lists. Courier Mail (2012).

30. Cenin D, O’Leary P, Lansdorp-Vogelaar I, Preen D, Jenkins M, Moses E. Integrating personalised genomics into risk stratification models of population screening for colorectal cancer. ANZ J Public Health (2016) 41(1):3-4. doi:10.1111/1753-6405.12587

31. Bampton PA, Sandford JJ, Young GP. Applying evidence-based guidelines improves use of colonoscopy resources in patients with a moderate risk of colorectal neoplasia. Med J Aust (2002) 176(4):155-7.

32. Siegel RL, Jemal A, Ward EM. Increase in incidence of colorectal Cancer among young men and women in the United States. Cancer Epidemiol Biomarkers Prev (2009) 18(6):1695-8. doi:10.1158/1055-9965.EPI-09-0186

33. Troeung L, Sodhi-Berry N, Martini A, Malacova E, Ee H, O'Leary P, et al. Increasing incidence of colorectal cancer in adolescents and young adults aged 15-39 years in western australia 1982-2007: examination of colonoscopy history. Front Public Health (2017) 5:179. doi:10.3389/fpubh.2017.00179

34. Australian Institute of Health and Welfare. National Bowel Cancer Screening Program: Monitoring Report 2013-14. Canberra: Australian Institute of Health and Welfare (2015). Report No.: Cat No: Can 92.

35. Gimeno-García AZ. Factors influencing colorectal cancer screening participation. Gastroenterol Res Pract (2012). doi:10.1155/2012/483417

36. Win AK, Macinnis RJ, Hopper JL, Jenkins MA. Risk prediction models for colorectal cancer: a review. Cancer Epidemiol Biomarkers Prev (2012) 21(3):398-410. doi:10.1158/1055-9965.EPI-11-0771

37. van der Meulen M, van Hees F, Korfage I, van Heijningen E, van Ballegooijen M, de Koning HJ, et al. Surveillance after Polypectomy - Towards Successful Implementation of Guidelines. Netherlands: The Netherlands Organisation for Health Research and Development (2015).

38. Laiyemo AO, Pinsky PF, Marcus PM, Lanza E, Cross AJ, Schatzkin A, et al. Utilization and yield of surveillance colonoscopy in the continued follow-up study of the Polyp Prevention Trial. Clin Gastroenterol Hepatol (2009) 7:562-7. doi:10.1016/j.cgh.2008.12.009

39. Pinsky PF, Schoen RE, Weissfeld JL, Church T, Yokochi LA, Doria-Rose VP, et al. The yield of surveillance colonoscopy by adenoma history and time to examination. Clin Gastroenterol Hepatol (2009) 7:86-92. doi:10.1016/j. cgh.2008.07.014

40. Robertson DJ, Burke CA, Welch G, Haile RW, Sandler RS, Greenburg R, et al. Using the results of a baseline and a surveillance colonoscopy to predict recurrent adenomas with high-risk characteristics. Ann Intern Med (2009) 151:103-9. doi:10.7326/0003-4819-151-2-200907210-00007

41. Lieberman DA, Rex DK, Winawer SJ, Giardiello FM, Johnson DA, Levin TR. Guidelines for colonoscopy surveillance after screening and polypectomy: update by the US Multi-Society Task Force on Colorectal Cancer. Gastroenterology (2012) 143(3):844-57. doi:10.1053/j.gastro.2012. 06.001 
42. Cairns S, Scholefield J, Steele R. British Society of Gastroenterology: guidelines for colorectal cancer screening and surveillance. Gut (2010) 59:666-90. doi:10.1136/gut.2009.179804

43. Dekker E, van Leerdam ME, Hazewinkel Y, Sanduleanu S, Vasen HF, LansdorpVogelaar I, et al. Dutch Guideline Colonoscopy Surveillance. Rotterdam: Dutch Association of Gastroenterology Liver Physicians (2013).

44. Dear R, Barratt AL, Evans A, Simes J, Newsom J, Kent D, et al. Identifying and prioritising gaps in colorectal cancer trials research in Australia. Med J Aust (2012) 197(9):507-11. doi:10.5694/mja12.10623

45. Brook EL, Rosman DL, Holman CDJ. Public good through data linkage: measuring research outputs from the Western Australia Data Linkage System. ANZ JPublic Health (2008) 32(1):19-23. doi:10.1111/j.1753-6405.2008. 0010160.x

46. Kelman CW, Bass AJ, Holman CDJ. Research use of linked health data: a best practice protocol. ANZ J Public Health (2002) 26(3):251-5. doi:10.1111/j.1467842X.2002.tb00682.x

47. Western Australian Data Linkage System (WADLS). Western Australia: Department of Health (2016). Available from: http://www.datalinkage-wa. org.au/

48. Lansdorp-Vogelaar I, Kuntz KM, Knudsen AB, van Ballegooijen M, Zauber AG, Jemal A. Contribution of screening and survival differences to racial disparities in colorectal cancer rates. Cancer Epidemiol Biomarker Prev (2012) 21(5):728-36. doi:10.1158/1055-9965.EPI-12-0023
49. Loeve F, Boer R, van Oortmarssen GJ, van Ballegooijen M, Habbema JD. The MISCAN-COLON simulation model for the evaluation of colorectal cancer screening. Comput Biomed Res (1999) 32(1):13-33. doi:10.1006/ cbmr.1998.1498

50. Cenin D, St John J, Slevin T, Ledger MJ, Lansdorp-Vogelaar I. Optimising the expansion of the National Bowel Cancer Screening Program. Med J Aust (2014) 201(8):456-61. doi:10.5694/mja13.00112

Conflict of Interest Statement: The authors declare that the research was conducted in the absence of any commercial or financial relationships that could be construed as a potential conflict of interest.

The reviewer JC declared a shared affiliation, with no collaboration, with one of the authors MB to the handling Editor.

Copyright (C) 2017 Preen, Lansdorp-Vogelaar, Ee, Platell, Cenin, Troeung, Bulsara and O'Leary. This is an open-access article distributed under the terms of the Creative Commons Attribution License (CC BY). The use, distribution or reproduction in other forums is permitted, provided the original author(s) or licensor are credited and that the original publication in this journal is cited, in accordance with accepted academic practice. No use, distribution or reproduction is permitted which does not comply with these terms. 